\title{
Entrenamiento basado en la simulación como medio de prevenir conflictos éticos en el proceso enseñanza-aprendizaje
}

\author{
J.A. Garrido-Sanjuán
}

Después de leer la buena revisión sobre el entrenamiento basado en la simulación publicada por Vázquez-Mata y Guillamet-Lloveras [1], esta carta tiene como objetivo aportar algunas puntualizaciones por si pueden contribuir a profundizar en un campo como es el de la ética de la educación médica, que ha generado hasta ahora escasa atención y reflexión.

Aunque la revisión enuncia en algún momento la seguridad de los pacientes y la preservación de sus derechos como circunstancias que aconsejan que el entrenamiento en simulación anteceda a las actuaciones con el paciente, se incide escasamente en la importancia de la simulación como medio de evitar problemas éticos que se pueden producir en los procesos de aprendizaje con los enfermos [2] y de los principios de la bioética como otros factores promotores de la simulación. El abordaje desde los principios de la bioética permite defender el aprendizaje basado en la simulación desde su papel de salvaguarda del principio de 'no maleficencia' o 'buena práctica clínica' en los procesos de aprendizaje.

Algún autor ha abordado el análisis de estos problemas éticos desde su conflicto con el imperativo categórico kantiano [3]: 'los profesionales sanitarios deben tratar siempre a los pacientes como fines en sí mismos, y nunca sólo como medios'. Por tanto, protegemos la dignidad de las personas si, aunque sean tratadas también como medios (el imperativo kantiano considera que esto es inevitable en muchas ocasiones), este trato se articula de forma responsable con el fin. La responsabilidad es lo que permite articular medios y fines en las situaciones concretas. Aquí, la responsabilidad estará en la ubicación de la utiliza- ción de simuladores de forma adecuada dentro de una secuencia recomendable de minimización de riesgos [2] que permitirá disminuir los potenciales conflictos éticos generados especialmente por las primeras interacciones de los profesionales en formación con los pacientes:

1. Adecuado aprendizaje de las bases teóricas y secuencia del procedimiento a realizar (conocimiento).

2. Ver realizar el procedimiento a personas expertas (ver hacer).

3. Realizar el procedimiento en condiciones experimentales: maniquíes, simuladores... (simulación).

4. Haber realizado procedimientos que le precedan en complejidad.

5. Práctica clínica tutelada.

6. Práctica clínica autónoma.

El proceso así realizado, junto a una mejora de la supervisión asegurando que la decisión de que un especialista en formación realice la atención a un paciente estará determinada por su nivel de formación y el grado de complejidad del proceso del paciente, permitirá defender que la atención del paciente sea realizada por residentes. Dicha prestación de asistencia, así argumentada, puede defenderse dentro del principio bioético de justicia, definido como tratar a todas las personas con igual consideración y respeto, no discriminándolas, con distribución de las cargas (en este caso, el ser sujeto de un proceso de aprendizaje) por igual entre los posibles afectados $[2,4]$.

Por tanto, el conocimiento del lugar que debe ocupar la simulación desde el punto de vista del
Servicio de Medicina Interna. Jefe de Estudios de Formación Especializada. Área Sanitaria de Ferrol. Ferrol, A Coruña, España.

Correspondencia Dr. Juan Antonio Garrido Sanjuán. Servicio de Medicina Interna. Jefe de Estudios de Formación Especializada. Área Sanitaria de Ferrol. Avda. de la Residencia, s/n. E-15405 Ferrol (A Coruña).

E-mail

ja_garrido@terra.es 
aprendizaje técnico y de los procesos comunicativos y de relación, y desde el punto de vista de la bioética, ha de formar parte del conocimiento a adquirir por los tutores de residentes [5].

Los escenarios simulados, como bien reseñan los autores, son también herramientas para la evaluación tanto formativa como sumativa. Siendo la evaluación un proceso moral, que supone una responsabilidad ética de los formadores frente a la sociedad, aparece aquí otro medio por el cual la simulación aporta una mejora ética al proceso $[2,6]$.

En conclusión, la mejora en medios de simulación no sólo supone un avance en la formación técnica de nuestros profesionales, sino también una reducción en los potenciales conflictos éticos, ya que nos puede ayudar a ser proactivos y no sólo reactivos en este campo. De nuevo, como en la práctica clínica, los valores (ética) vinculados a los hechos (técnica).

\section{Bibliografía}

1. Vázquez-Mata G, Guillamet-Lloveras A. El entrenamiento basado en la simulación como innovación imprescindible en la formación médica. Educ Med 2009; 12: 149-55.

2. Garrido JA. Conflictos éticos en el aprendizaje de los residentes. An Med Interna (Madrid) 2006; 23: 493-502.

3. Morvan PL, Stock B. Medical learning curves and the Kantian ideal. J Med Ethics 2005; 31: 513-8.

4. Jagsi R, Lehmann LS. The ethics of medical education. BMJ 2004; 329: 332-4.

5. Garrido-Sanjuán JA, García-Álvarez MA, Iglesias-Olleros A, Lago-Canzobre S, Lago-Deibe FI, Ramil-Hermida JL. Aprendiendo a ayudar a aprender. Historia de 10 años de formación de tutores de residentes en Galicia. Educ Med 2009; 12: 157-68.

6. Prados JD, Santos MA. La evaluación de los MIR como un proceso de aprendizaje. Med Fam (Andalucía) 2000; 1: 78-83. 